\title{
Selling of Products: The Use of Single-Electrode Wireless EEG in Consumer Behavior
}

Venta de productos: el uso de EEG inalámbrico de un solo electrodo en el comportamiento del consumidor

Yaromir Muñoz ${ }^{1}$, Francisco López Gallego ${ }^{2, *}$, Alejandro Arias Salazar ${ }^{1}$, and Maribel Serna Rodríguez²

\begin{abstract}
The results of three different groups of customers, each exposed to a different sales technique, were compared in order to evaluate which sales technique was more effective for achieving higher levels of sustained attention. The study used the Neurosky headband to measure brainwaves in millivolts. The three compared sales techniques were: 1) the training technique for sale, termed as structured by the AIDA model; 2 ) the traditional sale, here called unstructured; 3 ) and a structured technique with the help of simultaneous stimulation by several neuroattentional pathways, prescribed by the developments of the neuroscience of consumption (CN). The results showed a statistically significant difference in achieved sustained attention levels, presenting higher levels in clients exposed to the sales training technique and ower scores in those exposed to one of the techniques used by the $\mathrm{CN}$. These results are discussed in relation to the concept of sustained attention in clients when the stimulation of a single neuroattentional pathway is used as compared to the activation of several pathways simultaneously.
\end{abstract}

\section{Resumen}

Con el objetivo de conocer qué tipo de técnica de venta es más efectiva en lograr mayores niveles de atención sostenida, se compararon los resultados obtenidos por tres grupos de clientes expuestos, cada uno, a una técnica de venta de un mismo producto. Para el efecto se recurrió a la medición en milivoltios de ondas cerebrales de atención a través de diademas Neurosky. Las tres técnicas de venta comparadas fueron: 1) la técnica de entrenamiento en venta, estructurada según el modelo AIDA; 2) la venta tradicional, denominada aquí como no estructurada; 3 ) y una técnica estructurada con ayuda de estimulación simultánea por varias vías neuroatencionales, prescrita por los desarrollos de la neurociencia del consumo (NC). Los resultados mostraron una diferencia estadísticamente significativa en los niveles de atención sostenida alcanzados, presentando mayores niveles en los clientes expuestos a la técnica de entrenamiento en venta y menores puntajes en aquellos expuestos a una de las técnicas usadas por la NC. Estos resultados se discuten en relación con el concepto de atención sostenida en los clientes, cuando se recurre a la estimulación de una vía neuroatencional en comparación con la activación de varias vías simultáneamente.

\section{Keywords:}

Sales Techniques, Structured Sale, Unstructured Sale, Attention, Neurocognition, EEG, Consumer Behavior, Neurosky Mindwave.

\section{Palabras Claves:}

Técnicas de venta, venta estructurada, venta no estructurada, atención, neurocognición, EEG, comportamiento del consumidor, Neurosky Mindwave.

1. Departamento de marketing, Universidad EAFIT, Medellín, Colombia.

2. Departamento organización y gerencia. Universidad EAFIT, Medellín, Colombia.

* Corresponding author. flopez@eafit.edu.co

Manuscript received 26-11-2018; revised 18-12-2018; accepted 08-04-2019

\section{Introduction}

The consumption of goods and services constitutes a central axis in consumer psychology, marketing and advertising. As a result, recognizing the cognitive, behavioral and neurophysiological variables involved in the buying and selling of products is crucial to outlining new strategies, techniques and designs that promote collective benefit by stimulating consumption in the population.

In this context, commercial marketing, and cognitive and social psychology have made significant progress in understanding purchasing behavior and how to maintain, strengthen, and segment it. However, psychophysiological approaches are changing the relationship between the consumer and the market. 
In this regard, the selection of relevant stimuli and the subsequent requirements related to the filtering, focus, sustaining and temporality of the stimulus of interest bring a critical function for human evolution and adaptation to attention. This condition is fundamental for the recognition of brand positioning and the keys to consumption that derive from advertising. Likewise, attentional processes are not static, functioning as an underlying emergent property of mental representation at the neural level that contributes to hierarchical processes of storage of information permeated by experiences, motivations and context (Lewis-Peacock \& Postle, 2012; Ruiz-Contreras \& Cansino, 2005). Therefore, rather than a variable that operates independently, attention requires the joint efforts of cognitive "units" underlying cortical networks that add to the efficient implementation of the task with specific responsibilities.

Attention is influenced by two general mechanisms of stimulus processing: bottom-up processing, which operates when the stimuli influence the probability of perceptually standing out, such as the type of label or its position in the package; and top-down processing, which starts when the individual seeks a purpose and directs his attention through motivational relevance, here including temporal limitations and the goals of the consumer. Additionally, according to Kahneman (quoted by Bruya \& Tang, 2018), attention is a neurocognitive process of limited capacity that involves a metabolic expenditure to perform filter functions of environmental stimuli to decide which are more relevant, and grant them priority through concentration. In fact, it is the sustained or voluntary attention from its two components, duration and consistency, which allow the efficacy of the execution.

Up to now, different studies have focused their interest on determining specific attention pathways, whether auditory, olfactory, or somatoestheticproprioceptive, to identify which of these sensory pathways can be more effective in capturing the attention of the consumer regarding the impact of stimuli. (Vechiatto, Kong, Maglione \& Wei, 2012). These studies have privileged visual pathways, as shown by Aslam, (2006), Kalliny and Gentry, (2010), and Añaños, (2015).

From the neurocognitive point of view, the definition of attention goes beyond a simple function and can be understood as the selective targeting of consciousness, which filters and discards unwanted information. According to Sohlberg and Mateer (2001), attentional functions can be classified as: 1) Arousal or cortical energy (with the action of the activating reticular formation), which allows the organism and the brain to be awake or activated;2) Volume of apprehension, which is linked to the number of elements of possible evocation following the organism's exposure to information; 3) Targeting, which consists of the ability to invest attentional resources in one or more relevant stimuli, discarding those of little importance; 4) Selective attention linked to the preference (selection) of some stimuli over others; 5) Divided attention, which allows the response to two tasks of selective attention; and 6) Sustained attention, which is defined as the ability to maintain attention consistently during a determined unit of time and is the object of the present investigation.

So far, studies of attentional function have been useful for the analysis of consumer behavior; these research projects have allowed the reformulation of sales strategies, including research on marketing and advertising that privileges the design of protocols that lead to greater efficiency in the control of time favoring selective attention. In particular, the empirical techniques evolving from the emergent processes of different market dynamics and their sellers have developed sales strategies that seek to give a planned order to the sales process. One of these strategies is known as the Attention, Interest, Desire and Action model (referred to as AIDA) proposed by Lewis in 1908 and improved by Strong, Jr. (1925). This model gives greater value to the first moment known as the capture of customer concentration (sustained attention), from which the subsequent moments are revealed. Currently, with the development of the various tools of the neuroscience of consumption, it has been suggested that more concurrent stimuli lead to a higher level of customer attention (Hultén 2011). For this reason, there has been more interest in the analysis of variables such as the attractiveness of the product and packaging (Morin, 2011), the effectiveness of the advertising messages, the preference in colors and shapes and the more persuasive types of argument for the receiver, among others (Hubbert \&Kenning, 2008).

However, even though marketing studies reflect the results of sales techniques based on the efficacy of transactions, there are no studies that give comparative support among sales techniques in order to maintain the customer's focus of attention. The implications of attentional function and its relationship with sales techniques have permeated the scope of the AIDA model, which synthesizes four phases of the process people follow with a salesperson. This gives emphatically greater relevance to the first moment. After attracting the customer's attention to a stimulus, it generates great interest if it is of sufficient strength to allow it to connect with higher-level motivations. This in turn can lead the customer's deepening search for information to materialize in a desire to acquire the product, meaning the effective sale for marketing (Soto \& Restrepo, 2008) and the purchase for the customer. The consideration of the relevance of the attention provided by the AIDA model implies a process of 
structured sequencing (Strong Jr., 1925), and begins with the seller's attempt to maintain the customer's attention and stimulate their interest.

Research on attention processing in marketing has also been repeatedly investigated through different neuropsychophysiological tools; in particular, the brain waves have been analyzed with the use of "Neurosky" (Crowley, Sliney, Pitt, \& Murphy, 2010), by virtue of being a versatile, portable and non-invasive technology. Its use in the measurement of the variation in attention in clients subjected to sales techniques is novel, since Neurosky has been used regularly to measure emotional response during the performance of several types of psychological tests (Crowley et al., 2010). In addition, the Mindwave device, developed by the Neurosky firm (http://neurosky.com/) uses a headband design to measure brain activity, allowing the low-cost and highperformance measurement of EEG signals, which can be used to analyze the individual's sustained attention.

The interest in learning about the proper use of moments of truth in the presentation of sales has led to a deepening of the study of levels of sustained or voluntary customer attention. This study uses the presentation of the same product within the sales process to answer the following question: which sales technique is more effective in achieving sustained attention of customers: the unstructured technique, the structured sales technique using the AIDA model or the prescribed technique according to the developments proposed by the consumer neuroscience?

This leads to formulating the first theoretical hypothesis of this investigation:

H1: The structured technique of deliberate training of salespeople (ST), which follows the guidelines of the AIDA model, will be more effective in achieving higher levels of sustained attention in the clients compared to the levels of attention achieved through the use of the unstructured technique (UT) and the technique based on consumer neuroscience (CN).

Based on the preceding arguments it could be presumed that the unstructured empirical techniques will attract more attention in from clients in comparison with other sales techniques where a great amount of sensorial stimuli are presented that are implemented by the neuroscience of consumption. That is to say, which uses several psychophysiological pathways of sensorial activation involved in simultaneous attentional functions (smell, taste, sound, etc.), to which is added the results obtained by Añaños (2015), showing that there are variations of the stimuli which can affect the performance of an individual's concentration for long periods of time. This would mean that the greater the number of stimuli, and depending on their sensory modality (whether auditory, visual or kinesthetic) attentional focus becomes more difficult and the task performance decreases (Pieters \& Wedel, 2004). Equally, the temporal space uncertainty that alludes to the degree of ignorance of the origin and the moment of appearance of the stimuli, leads to the loss of the ability to stay focused, and therefore sustained attention is diminished as well. This leads to the second theoretical hypothesis of this study:

H2: The unstructured sales technique, widely used in the market, is more effective in achieving higher levels of sustained attention in clients compared to the levels of attention reached through the use of the consumer neuroscience technique (CN).

The previous controversy can be settled by contrasting the formulation of the third theoretical hypothesis of research:

H3: The simultaneous presentation of several stimuli in a sales process, prescribed by the proposals of the Consumer Neuroscience (CN), means that the levels of sustained attention by the client will be lower than the levels of attention reached after the traditional technique (UT) and structured technique based on the AIDA model (ST).

The purpose of this investigation was to determine, through obtaining EEG signals (technique used in consumer neuroscience studies: $C N$ ) which of the three sales techniques is associated with greater sustained attention. The sales techniques that were analyzed were:

- The unstructured sale characterized by the presentation of the arguments of the product in an unstructured way (hereafter UT).

- The structured technique, under the criteria of improvement of commercial activity, based on the training of sellers guided by the AIDA model, hereafter referred to as ST (sales training).

- The technique that uses psychophysiological records of brain activation, which consists in the presentation of structured arguments about the product with additional sensory stimulation, namely: contact with the package, its smell, taste and the brand's sound (hereinafter $\mathrm{CN}$ ).

\section{Materials and Methods}

For the recording and quantitative analysis of brain waves during the exposure to the sales process of the same product with the use of the three mentioned techniques, the following procedure was followed: 92 participants were selected randomly from a population related to educational contexts. Inclusion- 
exclusion control questions were asked in order to select participants. Individuals who used medication to regulate the nervous system, who had a history of some psychiatric or previous neurological diagnosis, or who consumed psychoactive drugs were excluded. Participants also had to be over 18 years old and with no prior knowledge of the brand that was evaluated in this investigation.

With the above criteria, three groups were formed, and each participant was exposed to the corresponding sales technique:

1. First, a group of 30 people was selected and exposed to the product through a presentation with a structured and organized sales technique based on the AIDA model, proposed by Strong Jr., (1925), here called sales training (ST).

2. Second, another group of 31 people was exposed to the product with a traditional, unstructured technique (UT), formed empirically without the guidance of academic criteria.

3. Subsequently, the product was presented to a third group of 31 people through a structured format using a common technique in consumer neuroscience (CN) studies which relies on the addition of simultaneous sensory stimuli such as aroma, sound, image, visual stimuli, touch (packaging manipulation) and a reading of descriptors of attributes, characteristics and benefits of the product.

The measurement of the levels of attention and its variation at the time of sale was made with the Mindwave device, developed by the Neurosky firm (http://neurosky.com/), whose headband design allows the measurement of EEG signals; Neurosky allows the acquisition of signals through passive biosensors connected to electrodes that facilitate the collection of different representations of the EEG.

The data collection through the Mindwave experimentation device (http://neurosky.com/ biosensors/eeg-sensor/biosensors/) used in this study is a non-invasive and low-cost alternative for acquiring signals to monitor brain activity, in particular the evaluation of cognitive tasks related to the use of attentional resources related to working memory. These are relevant in the maintenance and manipulation of the stimuli associated with the selection, purchase and sale of products. In this research the use of the headband was done in a space controlled by noise and lighting; the headband was then accommodated and adjusted before the sales presentation. Each of the different groups were shown a nutritional powder supplement product with the smell and flavor of vanilla "IN Nutritional Complement" of current commercial circulation in local and national markets (Valencia \& Marin, 2016a, 2016b), but previously unknown by the participants. The three types of sales were made by the same seller (an actor) with a standard duration of six minutes.

Additionally, the Neurosky Mindwave system was used to analyze the interaction of two signals processed in real time, evaluated for the compilation of images obtained from the eyes of the participants when they looked at the product and the measuring of an EEG obtained from this device. Mindwave has a terminal that is located in the subject's front area (Fp1) and a reference electrode located near the ear (according to the 10-20 system), which allowed a determination of the concentration of the participants.

\section{Results}

The information was analyzed with the Statgraphics Centurion program (http://www.statgraphics.com/). Differences between the means of the attention index for each of the groups were calculated using the nonparametric hypothesis test of Kruskal Wallis and the differences between pairs of means of the attention indices were obtained using post hoc tests through the Bonferroni method.

Table 1 shows all the information related to the description of the three samples.

Table 1

Age parameters and participants by technique

\begin{tabular}{lllll}
\hline Variable & \multicolumn{1}{c}{ Levels } & \multicolumn{3}{c}{ Technique } \\
\hline \multirow{4}{*}{ Technique } & ST & ST & CN & UT \\
& CN & 30 & & \\
& UT & & 31 & \\
\hline Age & $30 \leq$ Age $\leq 39$ & 8 & 3 & 5 \\
& $40 \leq$ Age $\leq 49$ & 12 & 19 & 15 \\
& $50 \leq$ Age $\leq 59$ & 6 & 7 & 8 \\
& More than 60 & 4 & 2 & 3 \\
\hline
\end{tabular}

The attention measurements in each of the people were made with the Neurosky headband in units of millivolts (mv); the average levels are shown by group (Figure 1). Table 2 shows both the behavior of the means of the average attention index by group as well as descriptive statistics measures associated with said variable. 


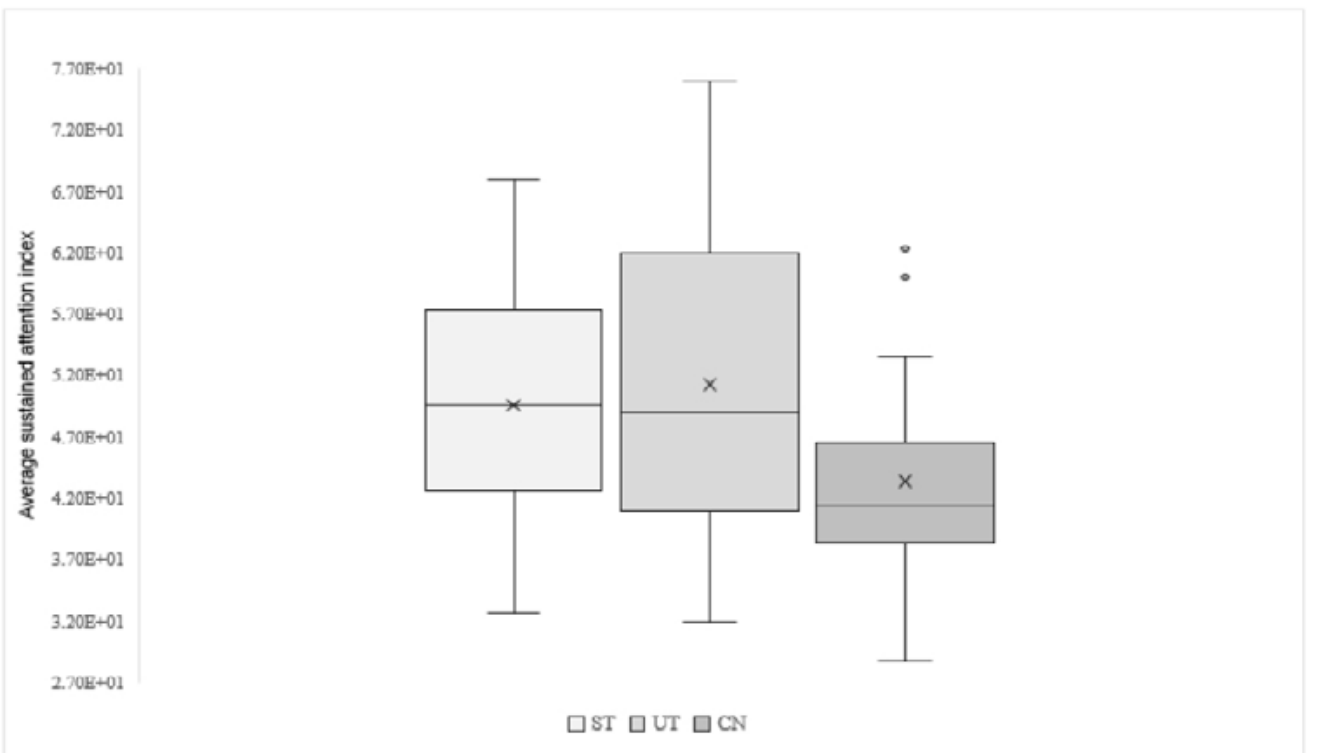

Figure 1. Boxplot of the behavior of the means of the attention index

Table 2

Average attention index by group

\begin{tabular}{llllllll}
\hline Technique & Count & Average & $\begin{array}{l}\text { Standard } \\
\text { deviation }\end{array}$ & Minimum & Maximum & Bias & Kurtosis \\
\hline ST & 30 & 49.57 & 911.6 & 32.62 & 68.02 & 0.08 & -0.47 \\
CN & 31 & 431.5 & 827.9 & 28.67 & 62.32 & 0.70 & 0.33 \\
UT & 31 & 512.9 & 122.7 & 32.00 & 76.00 & 0.44 & -0.91 \\
\hline Total & 92 & 479.8 & 105.4 & 28.67 & 76.00 & 0.57 & -0.29 \\
\hline
\end{tabular}

In order to test the raised theoretical hypothesis, to the following were evaluated: (a) the differences between the means of the attention index, and (b) the differences between pairs of means of the attention indices.

The evaluation of differences between the means of the attention index was carried out by applying the nonparametric hypothesis test of Kruskal-Wallis and under the following statistical assumptions: the variables follow a continuous distribution and are at least of ordinal type and the samples are independent and come from populations whose only difference is that at least one of them has a central location different from the others. For this non-parametric test, the formulations of the statistical hypotheses to be tested were:

$H_{0}: \theta_{i}=\theta_{j}, \forall_{i \neq j}, i, j: 1,2,3 \approx$ Average attention index for the three groups is equal

$H_{1}: \exists \theta_{i} \neq \theta_{j}, i, j: 1,2,3 \approx$ Average attention index for at least two of the three groups is not equal
Where, $\theta_{i}$ : average attention index for group i, where $i=1,2,3$.

The test statistic in this case was:

$$
\mathrm{H}=\frac{12}{N(N+1)} \sum_{j=1}^{k}\left[\frac{\left(\sum R_{j}\right)^{2}}{n_{j}}\right]-3(N+1) \sim \chi_{(k-1)}^{2}
$$

Where, $\mathrm{N}$ : the sum of the sample size of the three groups

$R_{j}$ : the sum of the ranges of the sample of the group $j$, where $j=1,2,3$

$n_{j}$ : the sample size of group $\mathrm{j}$

$\mathrm{k}$ : the number of groups

The results for this test are shown below:

Table 3

Kruskal-Wallis Test

\begin{tabular}{lll}
\hline Technique & Sample size & Average Range \\
\hline ST & 30 & 524.33 \\
CN & 31 & 342.42 \\
UT & 31 & 530.16 \\
\hline
\end{tabular}

Statistic $=9.862 \quad P$ - value $=0.007$ 
In Table 3 it is evident that because $p$ had a value of $0.007<\boldsymbol{\alpha} 0.05\left(\chi_{2}^{2}=9.862\right.$, pvalue $\left.<0.05\right)$, the null hypothesis is not accepted with a confidence level of both $95 \%$ and $99 \%$. Thus, there is not enough evidence to affirm that the average attention indices are the same for the three groups, and therefore it is determined that there is a significant statistically difference between the average attention indices under these confidence levels.

On the other hand, the evaluation of the differences identified between pairs of means of the attention indices was carried out by applying the respective post hoc tests using the Bonferroni method. For this test by pairs of means, the formulation of the hypothesis was the following:

$H_{o}: \theta_{i}=\theta^{j} \approx$ The population mean of the average attention index group $_{i}$ - The population mean of the average attention index group $_{j}=0$

$H_{1}: \theta_{i} \neq \theta_{j} \approx$ The population mean of the average attention index group $_{i}-$ The population mean of the average attention index $\operatorname{group}_{j} \neq 0$

The threshold above which the difference between the two means compared will be statistically significant and below which it will not is defined by the following factor:

$$
C D_{k w}=z_{a d j} \sqrt{\frac{N(N+1)}{12}\left(\frac{1}{n_{i}}+\frac{1}{n_{j}}\right)}
$$

Where, $\mathrm{z}_{\mathrm{adj}}$ : $\mathrm{z}$ value above which falls a proportion of cases corresponding to the value

$\alpha_{F W} / 2 c$.

$\alpha_{F W}:$ maximum error rate type I

c: total number of comparisons that are made and denoted by $\mathrm{c}=[k(k-1)] / 2$

The results for this test are shown below:

Table 4

95\% confidence intervals

\begin{tabular}{llll}
\hline Contrast & Sig. & Difference & +/- Limits \\
\hline ST - CN & $*$ & 181.914 & 163.715 \\
ST - UT & & -0.58279 & 163.715 \\
CN -UT & $*$ & -187.742 & 162.368 \\
\hline
\end{tabular}

* indicates a significant difference.

The results of Table 4 show that there are statistically significant differences marked with an asterisk between the ST groups and the CN group (18.1914> 16.3715), as well as between the CN group and the UT (18.7742 $>16.2368)$. The above indicates that the average of the attention index for the ST group is higher than for the $\mathrm{CN}$ group, and that the average attention index for the sales technique group UT is greater than for the $\mathrm{CN}$ technique group. Thus, the CN group is the one with a lower average sustained attention index in relation to the other two groups. All this can be seen in the following Figure 2:

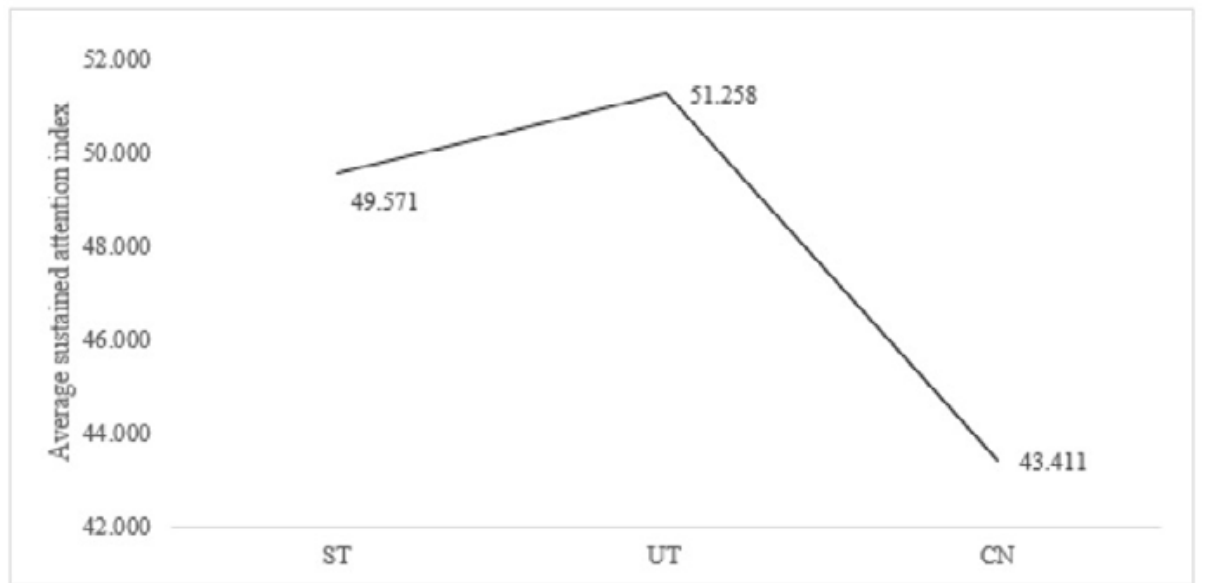

Figure 2. Representation of the means by group for the indices of sustained attention.

Table 4 allows the generation of the following analyses with respect to the theoretical hypotheses proposed:

1. The first theoretical hypothesis is partially confirmed: although there is a positive and statistically significant difference between the sales training group (ST) and the group that used proper techniques from consumer neuroscience studies (CN), there is not a statistically significant difference between the ST group and the unstructured sales group (UT).
2. The second theoretical hypothesis is totally confirmed since a significant statistically negative difference occurs between the $\mathrm{CN}$ group and the unstructured sales group (UT).

3. The third theoretical hypothesis is fully confirmed because both a statistically significant negative difference between the $\mathrm{CN}$ group and the UT group are presented, as well as a positive and statistically significant difference between the ST group and the $\mathrm{CN}$ group. 


\section{Discussion}

Based on the use of Neurosky Mindwave, the significant differences found in the average attention levels between the groups analyzed can be discussed. First, the result of the application of the sales training technique (ST) was partially confirmed only against the $\mathrm{CN}$ technique, which could mean that the traditional method of structured sale based on the AIDA model proved to be more effective in attracting customer attention than the NC method. This result could be due to two factors: 1) The consecutive order of presentation of the arguments, and 2) the predominance of the stimulation of only two sensory pathways for the attentional input, in this case visual and auditory. To this experimental situation the following condition is added: by stimulating only these two pathways, the participants had fewer distractions inherent to the presentation of various concurrent stimuli that come by different attentional pathways, as proposed by the guides that use psychophysiological tools to describe consumer response. This would mean that the supposed benefit suggested by some devices using the neuroscience of consumption, consisting of capturing attention by the simultaneous use of various stimuli to activate several attentional pathways at the same time would operate in reverse; that is to say it penalizes concentration levels because the occurrence of stimuli would become a distractor.

Second, when comparing the results of attention levels achieved by the client by the application of the sales training technique (ST) and non - structured technique (UT), there were not significant differences. This is due to the fact that despite an orderly structure being presented in the first and not the second case, both share the characteristic of the use of only two attentional pathways, the visual and the auditory. Therefore, the link between the results and the sales technique doesn't respond to the order of the presentation, as was previously hypothesized.

However, the results of the comparison between the unstructured sales technique (UT) and the CN technique completely confirmed the second working hypothesis. This is because when the salesperson stimulates only the auditory field of the client through the use of their voice and not letting the client discriminate the categories of the product like shape, smell, and taste perception, or to listen to the "jingle" of the brand or read the characteristics described in the package all techniques prescribed by a methodology focused on recognizing brainwave patterns $(\mathrm{CN})$. Instead, the salesperson manages to prevent the distracting effects.

Therefore, the large number of stimuli presented simultaneously using the technique of electroencephalographic records using Neurosky Mindwave behaved as attention distractors of a perceptual type and not as an aid to attract sustained attention. This can be understood as a conflict of stimuli versus the selective resource of customer attention.

Related to the third hypothesis, there is the possibility that the lower levels of average attention determined through the $\mathrm{CN}$ technique as compared with the other two sales techniques as confirmed in hypothesis three may be due to a failure to achieve an attentional connection due to the oversaturation of stimuli with the use of the tool used in the CN. By not reaching this connection, the desired attention was not achieved for the product that was presented. This happened because the oversaturation of stimuli can influence dorsolateral frontal processing, decreasing the performance of selective attention and restricting the processing of emotional signals by the pathway of sustained attention, both types of attention involved in the motivation and purchase decision.

With the $\mathrm{CN}$ technique significant measures of prefrontal activation were not reached, indicating the selection of the stimulus related to the sale. Although attention can be defined as the selected perception and directed towards a particular source of stimulation and effort or concentration on a task (Van-Zomeren \& Brouwer, 1994), this selective, directed perception or interest in something are modulated by the attentional function in conjunction with motivational aspects where the activators are exploration, concentration and vigilance. (Carrillo \& Restrepo, 2009; Lampit, Ebster \& Valenzuela, 2014). Therefore, if it is desired to reach a level of attention strong enough to activate the prefrontal cortex sensory components that fulfill the role of activators must be maintained while avoiding the aspects that limit the proper functioning of the "Attention Neurocognitive Pathway" like distractibility and the low performance that suggests the division of attentional tasks (divided attention), which are caused in the CN technique by the saturation of stimuli.

This research contributes to the discrimination of the scopes of EEG marketing wave analysis, one of the techniques used by consumer neuroscience, and its relationship with selection, the purchase and sale of products. These findings are consistent with Morin's (2011) analysis of on advances in neurotechnology to decipher consumer behavior. However, it is necessary to indicate some of the limitations that EEG wave recording entails for marketing studies. For example, not all changes in the taking of EEG records suggest a brain response. This means that the presence of artifacts (the inclusion of human or technical noises in the taking of records) which behave similarly to the real activity of the EEG, and the potential presence of biological devices (that is, the ocular movement in itself) can alter the EEG signal. All this can affect the sensitivity of this type of study. Therefore, it is recommended that future studies, discriminate performance in the attentional function of the participants with neuropsychological 
tasks prior to the study of purchase and selection of products in order to obtain the base range of attentional performance in the selected sample.

\section{Conclusions}

The present investigation based its first presumption on techniques derived from sales training through the AIDA model, proposed by Lewis in 1908, collected and improved by Strong, Jr. (1925), who gave it a strong pre-eminence in the capturing of client attention. This would lead to better results when reaching higher levels of sustained attention in clients compared with the other two techniques it was compared with. The presumption was confirmed only as it pertains to one of them. The results of the test of the first hypothesis present a positive and statistically significant difference compared to the $\mathrm{CN}$ group. However, it was not confirmed by the group that was subjected to the unstructured sales technique (UT).

The second theoretical hypothesis was fully confirmed, as a negative and statistically significant difference was shown between the $\mathrm{CN}$ group and the unstructured sales group (UT). The latter reached higher levels of sustained attention than the group subjected to several stimuli simultaneously and in various attentional pathways, as suggested by the developments of neuromarketing techniques.

The third theoretical hypothesis is fully confirmed because there is both a statistically significant negative difference between the $\mathrm{CN}$ group and the unstructured sales group UT, and a positive and statistically significant difference between the sales training group (ST) and the $\mathrm{CN}$ group.

The results of this study are useful for both scholars in marketing and sales as well as sales executives:

- Low averages in attention levels observed in the CN technique compared to the other two techniques indicate that confidence in the prescriptions of the technique using electroencephalographic records has been overrated by academics and sales executives.

- The sales techniques can be analyzed and evaluated with new brain function measurements, which could generate an increase in the reliability of scientific information about brain function in areas related to study of marketing and sales in particular.

- This study suggests changes to sales and sales training techniques to reach the depth of sensory stimulation of "attentional neurocognitive pathways".

In addition, the findings of this study may be the first lights of a deeper evaluation of the brain - using scientific tools - of the many aspects involved in the act of selling. This permits a better visualization of the impact and knowledge of the concept of "Neuro-sales" (Ready, Burton \& Guix, 2010).

Finally, it should be said that the use of sensory sales stimuli in brainwave recording techniques (CN), should be presented in an orderly manner (temporary sequence) to avoid saturation and circumvent its potential function as a distractor. The proper use of these stimuli and their management and systematization in the form of presentation to the customer should be prescribed as a result of further research studies.

Acknowledgment to the Eafit University for the support to do this research.

\section{References}

Añaños, E. (2015). La Tecnología del Eye Tracke en adultos mayores: cómo se atienden y procesan los contenidos integrados de televisión. Revista científica de Educomunicación, 45 (23), 75-83. doi:10.3916/C45-2015-08

Aslam, M. (2006). Are you selling the right color? A Cross cultural review of color as a marketing cue. Journal of Marketing Communication, 12 (1), 15-30. doi:10.1080/13527260500247827

Bruya, B., \& Tang, Y. Y. (2018). Is attention really effort? Revisiting Daniel Kahneman's influential 1973 book attention and effort. Frontiers in psychology, 9, 1133. doi:10.3389/fpsyg.2018.01133

Carrillo, CM., \& Restrepo, FL. (2009). Efectos de un Entrenamiento Cognitivo de la atención en el funcionamiento de la memoria de trabajo durante el envejecimiento. Acta Neurológica Colombiana. 25(4): 244-251.

Crowley, K., Sliney, A., Pitt, I., \& Murphy, D. (2010, July). Evaluating a brain-computer interface to categorise human emotional response. In 2010 10th IEEE International Conference on Advanced Learning Technologies (pp. 276-278). IEEE.

Hubert, M., \& Kenning, P. (2008). A current overview of consumer neuroscience. Journal of Consumer Behaviour: An International Research Review, 7(4-5), 272-292. doi:10.1002/cb.251

Kalliny, M., \& Gentry, L. (2010). Marketing in the 22nd century: A look at four promising concepts. Asian Journal of Marketing, 4(3), 94105. doi: 10.3923/ajm.2010.94.105

Hultén, B. (2011). Sensory Marketing: The Multisensory Brand-Experience Concept. European Business Review. 23(3), 256-273. doi:10.1108/09555341111130245 
Lampit A, Ebster C, \& Valenzuela M. (2014) Multi-domain computerized cognitive training program improve performance of bookkeeping task: a matched-sampling active-controlled trial. Frontiers in Psychology, 5(794): 1-7. doi:10.3389/ fpsyg.2014.00794

Lewis-Peacock, J. A., \& Postle, B. R. (2012). Decoding the internal focus of attention. Neuropsychologia, 50(4), 470-478. doi:10.1016/j.neuropsychologia.2011.11.006

Morin, C. (2011). Neuromarketing: the new science of Consumer behaviour. Society, 48(2), 131-135. doi: 10.1007/s12115-010-9408-1

Pieters, R. \& Wedel, M. (2004). Attention capture and transfer in advertising: Brand, pictorial, and text-size effects. Journal of Marketing, 68(2), 36-50. doi:10.1509/jmkg.68.2.36.27794

Ready, R., Burton, K., \& Guix, X. (2010). PNL para Dummies. Barcelona: Grupo Editorial Planeta.

Ruiz-Contreras, A., \& Cansino, S. (2005). Neurofisiología de la interacción entre la atención y la Memoria episódica: Revisión de estudios en modalidad visual. Revista de Neurología, 41 (12), 733-743.

Sohlberg, Mc., \& Mateer, C. (2001). Cognitive Rehabilitation. An Integrative Neuropsichological Approach. The New York: Guilford Press.

Soto GJ. \& Restrepo NE. (2008). Entrenamiento para Vendedores. Bogotá: Grupo Editorial Norma, S.A.

Strong, E. K. Jr. (1925). The psychology of selling and advertising. New York: Mcgraw-Hill.

Valencia, E. \& Marín, A. (2016a). Impacto de la Utilización del Complemento Nutricional "IN", en el aumento del \% de la masa muscular durante el ejercicio en gimnasios. Revista de la Asociación Colombiana de Nutrición Clínica (ACNC); Abstr. In Press.

Valencia, E., \& Marín, A. (2016b) "Impacto de la Reducción del \% de desnutrición infantil con el Complemento Nutricional "IN" pediátrico, adicionado a la Bienestarina en el concepto de recuperación nutricional. Revista de la Asociación Colombiana de Nutrición Clínica (ACNC). Abstr. In Press.

Vechiatto, G., Kong, W., Maglione, A., \& Wei, D. (2012). Understanding the impact of TV Commercials. IEEE Pulse, 3(3), 42-47.

Van-Zomeren, AH., \& Brouwer, WH. (1994). Clinical Neuropsychology of Attention. New York: Oxford University Press. 